\title{
VIEWPOINT
}

\section{Hyperhomocysteinaemia, Helicobacter pylori, and coronary heart disease}

\author{
J J Y Sung, J E Sanderson
}

Department of

Medicine, Prince of

Wales Hospital, The

Chinese University of

Hong Kong, Shatin,

Hong Kong

JJY Sung

Correspondence to:

Dr J J Y Sung, Department

Dr J Y Y Sung, Department
of Medicine, Prince of Wales

Hospital, The Chinese

University of Hong Kong

Shatin, Hong Kong.

Accepted for publication

12 March 1996
$\mathrm{J}$ E Sanderson

\begin{abstract}
Hyperhomocysteinaemia and Helicobacter pylori infection have recently been implicated in the pathogenesis of coronary artery disease. These two risk factors, though they seem unrelated, could be linked by a deficiency of vitamins and folate caused by chronic gastritis in $\boldsymbol{H}$ pylori infection. This nutritional defect could lead to failure of methylation by 5 methyl-tetrahydrofolic acid and thus exacerbate the accumulation of homocysteine in susceptible patients. Homocysteine is toxic to endothelial cells and results in coronary artery disease.
\end{abstract}

(Heart 1996;76:305-307)

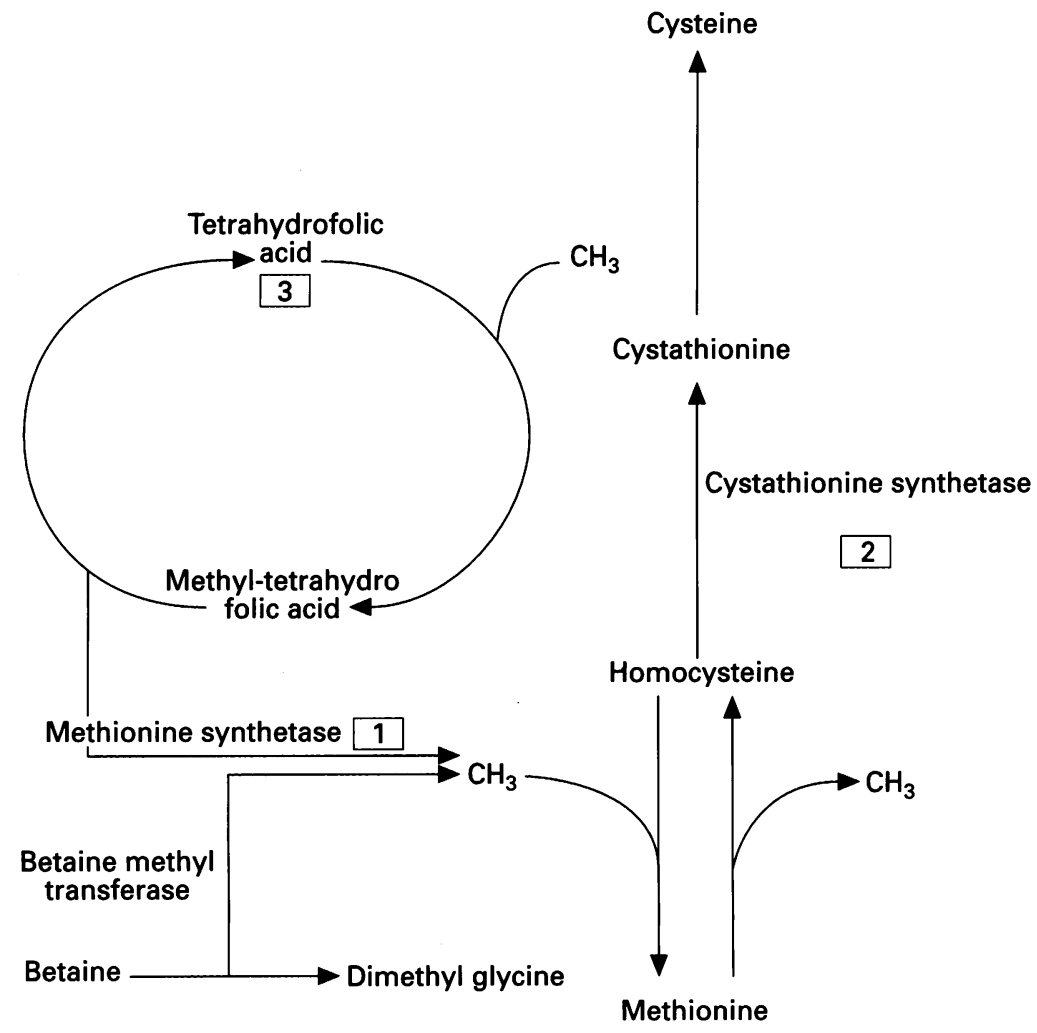

(1) Cobalamin dependent

(2) Depends on intake and absorption

(3) Pyridoxine dependent

Figure 1 Metabolism of homocysteine.
Keywords: hyperhomocysteinaemia, Helicobacter pylori, coronary heart disease

Coronary artery disease causes high morbidity and mortality in almost every ethnic group. Conventional risk factors such as hyperlipidaemia, hypertension, and cigarette smoking do not account for all cases of coronary artery disease. Recently, many investigators have demonstrated that homocysteine concentrations are raised in adult patients with atherosclerosis and coronary, cerebral, and peripheral vascular diseases. ${ }^{1-3}$ In addition $H$ pylori, a bacterium causing chronic gastritis and peptic ulcers, has recently been associated with coronary heart disease. ${ }^{4}$ Yet the mechanism by which $H$ pylori infection leads to atherosclerosis is poorly understood. We propose a link between these two newly implicated risk factors in the development of coronary heart disease.

\section{Hyperhomocysteinaemia and coronary heart disease}

Homocysteine is a thiol-containing amino acid produced by demethylation of methionine. Half of the homocysteine formed goes through the trans-sulphuration pathway and the other half takes a methyl group from betaine (betaine methyl-transferase) or 5-methyltetrahydrofolic acid (methionine synthetase) (fig 1). Methionine synthetase is a cobalamindependent enzyme which is functionally impaired when vitamin B-12 metabolism is abnormal. Homocysteinuria, an autosomal recessive condition, is usually caused by a deficiency of the enzyme cystathionine $\beta$-synthetase. This enzyme is required for the conversion of homocysteine to cystathionine. These patients have excessively high circulating concentrations of homocysteine resulting in a high risk of premature arteriosclerosis and venous thrombosis. ${ }^{5}$ The mechanisms for the association of hyperhomocysteinaemia with atherosclerosis are still unclear. Animal studies have shown that homocysteine infusion causes epithelial damage. ${ }^{6}$ Homocysteine is directly toxic to endothelial cells. It also inhibits the secretion of nitric oxide from endothelial cells and this action facilitates platelet aggregation and vasoconstriction. ${ }^{7}$ Homocysteine may alter the balance between procoagulants and 
anticoagulants by selectively inhibiting the processing and secretion of thrombomodulin, reducing the activation of protein $\mathrm{C}$, and inducing a protease activator of coagulation factor $\mathrm{V} .{ }^{8}$

There have been reports of hyperhomocysteinaemia in adults (both white and Chinese patients) with premature coronary artery disease who lacked the other characteristics of homozygous homocystinuria. ${ }^{1-3}$ This was attributed to a heterozygous defect in cystathionine synthetase production. The raised serum homocysteine concentration showed no correlation with increased plasma concentrations of cholesterol, low density lipoprotein, or trigylceride; cigarette smoking; and hypertension. ${ }^{10}$ The odds ratios of hyperhomocysteinaemia for the development of coronary artery disease was 23.9 . This is much higher than the risk of hypercholesterolaemia, hypertension, and cigarette smoking for myocardial ischaemia. ${ }^{1}$ However, a very strong correlation was shown between poor vitamin intake or vitamin concentrations in plasma (especially vitamins B-6 and B-12 and folate) and hyperhomocysteinaemia. ${ }^{211}$ As cobalamin is an essential cofactor for methionine synthetase and because in folate deficiency there is a lack of 5-methyl-tetrahydrofolic acid, deficiency of these vitamins results in further accumulation of homocysteine. Indeed, very high homocysteine concentrations have been reported in patients with vitamin deficiency, especially when multiple vitamin deficiencies were present. ${ }^{112}$ Furthermore, vitamin supplementation can normalise homocysteine concentrations. ${ }^{13}$

\section{Helicobacter pylori infection and coronary artery disease}

$H$ pylori was first identified in patients with chronic gastritis as a Gram negative curved

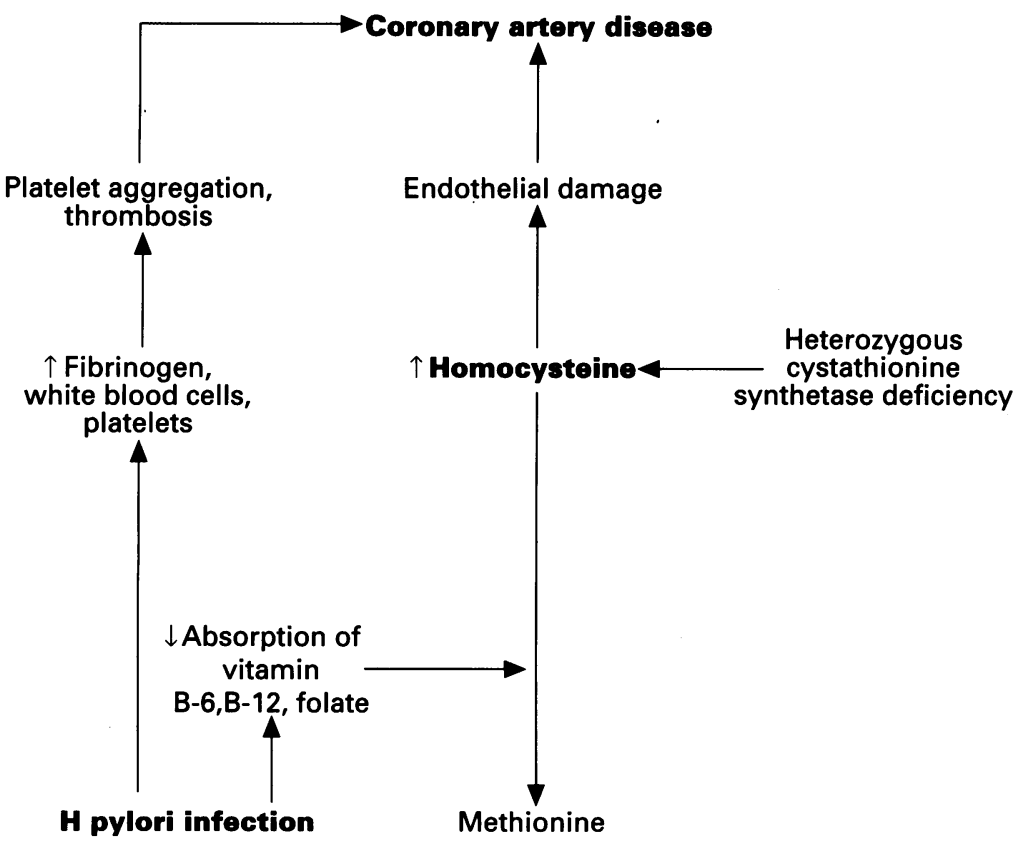

Figure $2 \mathrm{H}$ pylori infection, hyperhomocysteinaemia, and coronary artery disease. bacillus. ${ }^{14}$ After a decade of intensive research, the causal relation of this bacterium with peptic ulcer disease is widely accepted. ${ }^{15}$ Recently, studies have suggested that chronic infection with $H$ pylori may be associated with the risk of coronary artery disease. ${ }^{416}$ In a case-controlled study, it was found that seropositivity for $H$ pylori infection conferred a twofold risk of coronary heart disease. ${ }^{4}$ Like hyperhomocysteinaemia, the association of $H$ pylori infection with coronary artery disease is independent of other conventional risk factors such as smoking, hypertension, and hyperlipidaemia. ${ }^{17} \mathrm{~A}$ reverse causality - that is, that acute myocardial infarction causes a false positive serological test-is unlikely. $H$ pylori infection is acquired largely in childhood and there is no difference in antibody titre between patients with or without a history of previous myocardial infarction. ${ }^{17}$ However, the possible mechanism of a chronic infection by $H$ pylori leading to atherosclerosis is not known. One hypothesis is that chronic infection accompanied by persistent inflammation increases the concentration of acute phase reactants, such as fibrinogen and sialic acid, which are predictors of coronary artery disease. ${ }^{18-20}$ In a study by Patel et al fibrinogen concentration and total leucocyte count were higher in patients with cardiovascular disease and infected by $H$ pylori. ${ }^{17}$ However, the increase in fibrinogen concentrations was not confirmed in another study. ${ }^{21} H$ pylori infection may have other peripheral effects outside the stomach that predispose to the development of heart disease.

\section{$H$ pylori infection and nutritional deficiency}

$H$ pylori infection can cause more than gastroduodenal diseases. It has been shown that $H$ pylori infection reduces stature in children, probably because of a nutritional effect of gastric inflammation on absorption. ${ }^{22} 23$ In the elderly, $H$ pylori infection was associated with hypoalbuminaemia that was not explained by diet. ${ }^{24}$ Because vitamin B-12 absorption depends on the secretion of intrinsic factors by the parietal cells, gastric dysfunction commonly causes a malabsorptive state. Patients infected by $H$ pylori causing gastritis have been shown to suffer from malabsorption of cobalamin. ${ }^{25}$ Thus $H$ pylori infection can cause a nutritional deficiency, especially of vitamin B-6, vitamin $\mathrm{B}-12$, and folate, and this will predispose to accumulation of homocysteine in heterozygotic patients. Furthermore, because $H$ pylori infection is frequently acquired in childhood and persists for long periods, a mild degree of nutritional deficiency may be present for many years and lead to the development of atherosclerosis.

\section{Hypothesis (fig 2)}

We propose that chronic $H$ pylori infection leads to malabsorption of vitamin B-6, vitamin B-12, and folate; failure of methylation; and hyperhomocysteinaemia. Homocysteine could 
be responsible for the arterial damage associated with $H$ pylori infection. This hypothesis, therefore, links two hitherto disparate and unexplained causes of coronary artery and peripheral vascular disease. This hypothesis should be readily amenable to testing by further studies.

1 Clarke R, Daly L, Robinson K, Naughten E, Cahalane S, Fowler $\mathrm{B}$, et al. Hyperhomocysteinemia: an independent risk factor for vascular disease. $N$ Engl f $\mathrm{Med} 1991$; 324:1149-55

2 Stampfer MJ, Malinow MR, Willet WC, Newcomer LM, Upson B, Ullmann D, et al. A prospective study of plasma homocysteine and risk of myocardial infarction in US physicians. $¥ A M A$ 1992;268:877-81.

3 Lolin YI, Sanderson JE, Cheng SK, Chan CF, Pang CP, Woo KS, et al. Hyperhomocysteinaemia and premature coronary artery disease in the Chinese. Heart 1996;76: 117-22.

4 Mendall MA, Goggin PM, Molineaux N, Levy J, Toosy T, Strachan D, et al. Relation of Helicobacter pylori infection

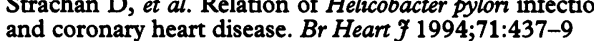

5 Grieco AJ. Homocystinuria: pathogenic mechanisms. Am f Med Sci 1977;273:120-32.

6 Harker LA, Slichter SL, Scott CR, Ross R. Homocystinemia: vascular injury and arterial thrombosis. $N$ Engl F Med 1974;291:537-43.

7 Stamler JS, Osborne JA, Jaraki M, Rabbini LE, Mullins M, Singel D, et al. Adverse vascular effects of homocysteine are modulated by endothelium-derived relaxing factor and related oxides of nitrogen. $\mathcal{F}$ Clin Invest 1993;91: 308-18.

8 Wu LL, Wu J, Junt SC, James BC, Vincent GM, Villiams $\mathrm{RR}$, et al. Plasma homocysteine as a risk factor for early familial coronary artery disease. Clin Chem 1994;40: 552-61.

9 Murphy-Chutorian DR, Wexman MP, Grieco AJ. Methionine intolerance: a possible risk factor for coronary artery disease. F Am Coll Cardiol 1985;6:725-730.

10 Kang SS, Wong PWK, Cook HY, Norusis M, Messer JV. Protein-bound homocysteine-a possible risk facto for coronary artery disease. $\mathcal{F}$ Clin Invest 1986;77: 1482-6.

11 Ubbink J, Vermaak W, Van der Merwe A, Becker P. Vitamin B12, vitamin B6 and folate nutritional status in men with hyperhomocysteinemia. Am $\mathscr{f}$ Clin Nutr 1993; 57:47-53.
12 Stabler SP, Marcell PD, Podell ER, Allen RH, Savage DG, Lindenbaum $J$. Elevation of total homocysteine in the serum of patients with cobalamin or folate deficiency detected by capillary gas chromatography-mass spectrometry. $\mathcal{F}$ Clin Invest 1988;81:466-74.

13 Dudonan NP, Wilcker DE, Wong J, Lynch JF, Macey D, Lundberg P. Disordered methionine/homocysteine metabolism in premature vascular disease. Its occurrence, cofactor therapy, and enzymology. Arterioscler Thromb 1993;13:1253-60.

14 Marshall BJ, Warren JR. Unidentified curved bacilli in the stomach of patients with gastritis and peptic ulceration. stomach of patients with

15 NIH Consensus Development Panel. Helicobacter pylori in peptic ulcer disease. $\mathcal{F} A M A$ 1994;272:65-9.

16 Martide-de-Argila C, Boixeda D, Fuertes A, Canton R, Barba M, Gisbert JP, et al. Helicobacter pylori infection and coronary heart disease. Gut 1995;37(suppl 1):A25.

17 Patel P, Mendall MA, Carrington D, Strachan DP, Leatham E, Molineaux N, et al. Association of Helicobacter pylori and Chlamydia pneumoniae infections with coronary heart disease and cardiovascular risk factor. Br Med भ 1995;311:711-4.

18 Yarnell JW, Baker IA, Sweetnam PM, Bainton D, O'Brien IR, Whitehead PJ, et al. Fibrinogen, viscosity and white blood cell count are major risk factors for ischemic heart disease. The Caerphilly and Speedwell collaborative heart disease studies. Circulation 1991;83:836-44.

19 Meade TW, Brozovic M, Chakrabarti RR, Haines AP, Imeson JD, Mellows S, et al. Haemostatic function and ischemic heart disease: principal results of the Northwick Park heart study. Lancet 1986;ii:533-7.

20 Lindberg G, Eklund GA, Gullberg B, Rastam L. Serum sialic acid concentration and cardiovascular mortality. $\mathrm{Br}$ Med $\mathcal{F}^{1991 ; 302: 143-6 .}$

21 Murray LJ, Bamford KB, Reilly DPJ, McCrum EE, Evans AE. Helicobacter pylori infection: relation with cardiovascular risk factors, ischemic heart disease and social class. Br Heart $¥$ 1995; 74:497-501.

22 Raymond J, Bergeret $M$, Benhamou $\mathrm{PH}$, Mensah $\mathrm{K}$, Dupont C. A two-year of $H$. pylori infection in children. $\mathcal{F}$ Clin Microbiol 1994;32:461-3

23 Mendall MA, Molineaux N, Levi J, Strachan D, Northfield TC. Association of $H$. pylori with diminished adult height. Gastroenterology 1994;106:A137.

24 Wong BCY, Ching CK, Lam SK, Lai KC, Hu WHC, Ong LY, et al. Association of Helicobacter pylori infection with hypoalbuminaemia and dietary habits. Gastroenterology 1995;108:260A.

25 Carmel R, Perez-Perez GI, Blaser MJ. Helicobacter pylori infection and food-cobalamin malabsorption. Dig Dis Sci 1994;39:309-14. 